\title{
DEPRESSION IN EPILEPSY
}

\section{Marco Mula MD PhD}

Atkinson Morley Regional Neuroscience Centre, St George's University Hospitals NHS Foundation Trust, London, United Kingdom

Department of Neuropsychiatry, South West London \& St George's Mental Health Trust, London, United Kingdom

Institute of Medical and Biomedical Sciences, St George's University of London, United Kingdom

\section{Corresponding author:}

Dr Marco Mula MD PhD

Atkinson Morley Regional Neuroscience Centre

St George's University Hospitals NHS Foundation Trust

Blackshaw Road

London SW17 0QT

United Kingdom

Tel: $\quad+442087254107$

FAX: +442087254591

Email:mmula@sgul.ac.uk

Word count for the abstract: 200 ;

Word count for the text: 6065 ;

Number of references: 88 


\begin{abstract}
Purpose of review: To review some aspects of the relationship between epilepsy and depression that have recently received increasing attention and may become major research topics in the near future.

Recent findings: Epidemiological studies show that depression and suicide are, in some cases, premorbid symptoms preceding the onset of the epilepsy. Suicide is also three times more frequent in epilepsy than in the general population. Reliable screening instruments for depression and suicidality in patients with epilepsy are now available but data from real life clinical settings are needed in order to develop shared clinical pathways between neurology and psychiatry. Data in children with epilepsy are still limited although it is well known that, outside epilepsy, almost $50 \%$ of adult patients with mood and anxiety disorders have a previous history during childhood. Despite increasing attention to the problem, the additional stigma associated with mental health problems still represents one of the major barriers to prompt diagnosis and treatment.
\end{abstract}

Summary: New studies will focus on the development of shared clinical pathways between neurology and psychiatry for mood disorders and suicide prevention. New global campaigns on the double stigma will support this process in areas where psychiatric comorbidities are still underdiagnosed and undertreated.

Key words (3-5): epilepsy, depression, suicide, stigma 


\section{Introduction}

The mutual relationships among epilepsy, seizures and mood disorders have been recognised for a long time, fascinating generations of clinicians and neuroscientists [1]. In his famous quotations, Hippocrates stated that "melancholics ordinarily become epileptics, and epileptics, melancholics: what determines the preference is the direction the malady takes; if it bears upon the body, epilepsy, if upon the intelligence, melancholy" [2]. Epilepsy is now recognized as a disorder of the brain characterized not only by an enduring predisposition to generate epileptic seizures, but explicitly also by the neurobiological, cognitive, psychological, and social consequences of this condition [3]. The new definition of epilepsy clearly highlights the importance of identifying and addressing behavioural problems of patients with epilepsy as these manifestations represent an integral part of the disease.

Mood disorders represent the most frequently encountered psychiatric comorbidities in patients with epilepsy [4] and are associated with poor quality of life (QoL )[5], seizure severity [6], side effects of AEDs [7], drug-resistance [8] and a poor outcome after epilepsy surgery [9]. However, mood disorders are, more often than not, ignored, unless they are severe enough to cause major problems or disability. This is due to multiple factors, including the patients' reluctance to volunteer spontaneously information about mental health issues, a paucity (or total lack) of a specific training of the treating neurologist to recognize these psychiatric comorbidities and a lack of time in very busy clinics to screen for them. During last few years, clinicians became increasingly interested in psychiatric comorbidities of epilepsy and screening instruments for mood [10] and anxiety disorders [11] are now available. In addition, epidemiological studies are now showing that some patients develop a complex neuropsychiatric condition characterised by depressive symptoms and recurrent seizures. This is a narrative review of some aspects of the relationship between epilepsy and depression that will probably receive increasing attention in the near future based on recent published data and new findings. Key references were identified through PubMed searches between 2011 and 2016 using the terms "epilepsy" and "depression". Additional publications were hand searched if relevant for the discussion.

\section{Depression as a premorbid condition}

A number of studies are now suggesting that depression can be per se associated with an increased risk of epilepsy. Data from the General Practice Research Database show that the incidence-rate ratio of depression is significantly higher in the three years preceding the onset of epilepsy [12]. A population-based study in Sweden shows that the age-adjusted odds ratio for the development of epilepsy is 2.5 for patients with a depressive disorder [13]. Other three population-based studies confirm that patients with a depressive disorder have a three to seven times increased risk to develop epilepsy [14,15][16]. A previous meta-analysis of Phase II and Phase III placebo-controlled trials of antidepressant drugs between 1985 and 2004 showed that subjects randomised to antidepressants other than clomipramine and bupropion are $69 \%$ less likely to develop seizures and patients randomised to placebo are 19 times more likely to have seizures as compared to the expected incidence in the general population [17]. All these evidence taken together clearly suggest that some patients with depression develop epilepsy as part of the "natural course" of the depressive disorder or that depression may represent a premorbid phase of some epileptic syndromes.

In terms of neurobiological mechanisms, despite a large number of studies investigating the neurobiological links between epilepsy and depression, the clear basis for the development of 
epilepsy in patients with depressive disorders is not fully clarified. It is well-known that depression and temporal lobe epilepsy share a disruption in the same brain networks but this is obviously not enough to explain the observed associations and, most importantly, the observed temporal sequences. Basic neuroscientists formulated a number of hypotheses mainly based on data from animal models. Low serotonin levels have been historically described in mood disorders but it seems now evident that they are present in epilepsy as well. In fact, similar findings are reported in animal models of epilepsy such as genetically epilepsy-prone rates [18], pilocarpine status epilepticus model in Wistar rats [19] and Rhesus monkeys [20]. It is still unclear whether there is a specific threshold in serotonin loss leading from depression to spontaneous seizures and which serotoninergic pathway is more likely to be responsible for this transition. Interestingly, a deletion of the 5HTC2 receptor subunit lowers the threshold for audiogenic seizures in mouse models of epilepsy [21] but further studies are needed.

Another coming area of research looking at the biological mechanisms shared by epilepsy and depression is that of stress. In reality, this is not entirely new as the role of the hypothalamic-pituitary-adrenal (HPA) axis in depression is well established. However, it is now evident that pretreatment with corticosterone accelerates the kindling process in rats [22] and this would be in keeping with the emerging literature on the potential role of stress in epilepsy [23]*** not only as a precipitant factor but also as a potential causative one [24]. The disruption in GABA and glutamate neurotransmissions used to be a classic finding in epilepsy but cumulative data are now showing similar findings in depression through a HPA mediated mechanism. In fact, steroids can modulate the expression and composition of GABA-A receptors promoting epileptogenesis and increasing brain excitability in general $[25,26]^{* *}$. As a result, GABA hypofunction is now also reported in patients with depression [27] and NMDA receptor antagonists are now tested not only as antiepileptic agents but also as antidepressants [28].

Advances in the neurobiology and molecular pharmacology of the relationship between depression and epilepsy are bringing into the epilepsy field neurochemical pathways, such as serotonin and melatonin, traditionally investigated for mood disorders, and completely new biological targets such as galanin receptors [29]. Nalutozan is a selective 5HT1A agonist currently under investigation for both anxiety and epilepsy while beprodone is a melatonin type 3 receptor agonist under Phase IIb development in drug-refractory localisation-related epilepsies [29]. Galanin is one of the most inducible neuropeptides and its biosynthesis is increased 2 to 10 -fold upon seizure activity in the brain. Agonists of Galanin receptor type 2 seem to have both anticonvulsant and analgesic/anxiolytic properties and a specific agonist (Nax 810-2) [4] is currently under preclinical investigation.

\section{Depression and anxiety in children}

Depression has been historically studied and investigated in the context of adult epilepsies. However, in the general population, anxiety disorders are much more common in children than in adults [30,31]. Diagnosis and management of mood and anxiety disorders in children have important implications. In fact, children with anxiety disorders seem to be at increased risk of further psychiatric comorbidities such as attention deficit hyperactivity disorder (ADHD) or conduct disorder [32]. In addition, half of adults with depression had a history of anxiety before the age of 15 [33]. For all these reasons, the American Academy of Child and Adolescent Psychiatry has recommended that children and adolescents are 
routinely screened for symptoms of anxiety [34]. It seems, thus, evident that both a careful assessment and a prompt treatment of depression and anxiety in children with epilepsy would prevent the development of major psychiatric disorders during adulthood.

Epidemiological studies of depression in children with epilepsy are still limited compared to the large number of publications in adults. A long-term prospective study in newly diagnosed children with epilepsy followed up for up to 9 years, reported a $13 \%$ prevalence of depression [35]. A large US nationwide survey found depression in $8 \%$ of children with current epilepsy, $7 \%$ of children with a previous history of seizures and $2 \%$ of controls [36] and similar figures were reported by a UK community-based study of children with epilepsy 5-15 years of age attending schools in Sussex [37]. Anxiety and depression seem to be more common in children with epilepsy and lower IQ, language delays or decreasing scores on neuropsychological assessment [38-40]. As already mentioned, children with anxiety are at increased risk of ADHD and it is now established that this is 2 to 3 times more frequent in epilepsy as compared to the general population [41]. In addition, a community-based survey in more than 1000 adult patients with epilepsy reported that ADHD-like symptoms are present in 1 out of 5 subjects and are associated with depression, anxiety, drug-resistance and poor quality of life [42]. The importance of ADHD should not be underestimated as it is a well-known risk factor for major psychiatric problems during adulthood such as alcohol and substance abuse, psychiatric hospitalisations and antisocial personality disorder [43]. All these evidence taken together suggest that some children with epilepsy can develop a complex neuropsychiatric condition characterised by mood and anxiety as well as cognitive and neurodevelopmental problems and this seems to be evident in children with even subtle neurological signs or cognitive problems. In fact, neurotypical (normal neurologic, cognitive, and imaging examinations) young adults with childhood-onset epilepsy do not present increased rates of psychiatric disorders [44].

But the relationship between depression and epilepsy in children is even more complex than that as many psychological factors are implicated as compared to adults. Dunn et al. found that the adolescent attitude towards the epilepsy and an external or unknown locus of control were predictors of depression [45]. The adverse effect of seizures on the family, limited emotional support, poor communication, inadequate support of child autonomy and maternal depression contribute to anxiety and depression in the child with epilepsy [45-47]. It is, therefore, evident that, apart from neurobiological variables, social variables, stigma and parental attitudes play a relevant role in mood and anxiety disorders in children with epilepsy. For all these reasons, tailored treatment approaches are needed and should include multidisciplinary approaches including psychotherapy, occupational and vocational therapy. In addition, the role of perceived stigma will receive increasing attention in prevention and management of mood disorders in children with epilepsy.

\section{Reducing mortality of epilepsy: suicide prevention}

While suicide represents $1 \%$ of all deaths in the general population, it accounts for $11.5 \%$ of all deaths in epilepsy. These figures are not so different from those of SUDEP that accounts for $18 \%$ of all deaths in epilepsy. However, as compared to SUDEP, suicide is still an unmentionable issue in epilepsy. Standard mortality ratio for suicide in patients with epilepsy is three times higher than the general population [48] and such a risk remains high even after excluding those with a history of psychiatric disorders and adjusting for socioeconomic factors [49]. A population-based study in England has shown that $25 \%$ of 
patients with epilepsy have a lifetime history of suicidal thoughts and more than $10 \%$ have a lifetime history of suicidal attempts [50]. Similar figures have been reported by another population-based study from Canada [51]. Several studies have attempted to identify reasons for such an increased risk. Historically, suicide has been linked to temporal lobe epilepsy [52] but more recent data failed to find such a close association [53]. Severity of the seizure disorder does not seem to be a relevant factor [54] while depression is, at present, the major risk factor $[55,56]$. It is likely that other, still unknown, biological factors contribute to the increased risk of suicide in epilepsy [57] given the bidirectional relationship between epilepsy and depression [12,16]. In fact, a recent study identified an association between suicide attempts and epilepsy even before the onset of seizures themselves, and independently of psychiatric disorders $[58]^{* *}$.

As already mentioned, suicide in epilepsy has long represented, and probably still represents, a taboo. In fact, if we analyse the whole literature on suicide in epilepsy, $50 \%$ of currently available indexed papers have been published in the ten years, while the remaining $50 \%$ in the preceding 30- 40 years [59]. The interest on suicide in epilepsy rapidly escalated during last few years and the US Food and Drug Administration (FDA) alert on the increased risk of suicidal ideation and behaviour in people taking antiepileptic drugs (AEDs) has probably contributed to that [60]. The FDA meta-analysis focused on multicentre-randomised placebo controlled trials of 11 AEDs. Spontaneously reported suicidality occurring during doubleblind trials with an AED (or within one day of stopping) were sought and categorized. Results suggested an increased suicidality risk in patients taking AEDs. The FDA results were received with great scepticism by clinicians and professional societies [61]. Some investigators questioned the validity of FDA findings, identifying serious methodological flaws [62]. However, there is no doubt that the FDA document has finally highlighted the issue of suicide in epilepsy. An expert consensus statement developed by an ad-hoc task force of the Commission on Neuropsychobiology of the International League Against Epilepsy (ILAE) stressed the need for screening instruments of suicide and clinical monitoring during clinical trials of AEDs [63].

Prevention is the only treatment for suicide but research on screening for suicide in epilepsy is still at a very early stage. The Columbia Suicide Severity Rating Scale (CSSRS) [64] is currently recommended to identify and monitor patients at high suicidality risk in clinical trials of AEDs [63]. It is available in several languages, and a validity study in epilepsy was published [65]. However, it is rather unrealistic to consider the CSSRS as a user-friendly clinical instrument to use in routine clinical practice for screening purposes. A cross sectional study compared the CSSRS, administered either in-person or using an Interactive Voice Response System (E-CSSRS) against the MINI, and showed good to excellent psychometric properties [65]. However, both the E-CSSRS and the MINI are time consuming and have to be administered by a trained health professional, becoming not cost-effective. Other authors suggested the use of item 9 of the Beck Depression Inventory [56] but the validity and psychometric properties of this method have never been investigated. The Neurological Disorders Depression Inventory for Epilepsy (NDDIE) was developed for the rapid and objective detection of a major depressive episode in patients with epilepsy [10]. It has shown to be a very practical and user-friendly screening instrument in any outpatient or inpatient setting. The NDDIE is now available in a number of languages and many clinicians are becoming increasingly familiar with this screening tool in their clinical practice. A recent study validated the use of item 4 of the NDDIE as a suicidality screening instrument, showing good psychometric properties [66]. Suicide may be considered an unmentionable issue by many neurologists, as they may feel uncomfortable in asking the patient directly. However, according to the NICE guidelines, suicidal ideation and intent should always be part of the 
assessment of depression. The NDDIE as a rapid suicidality-screening instrument represents an easy and straightforward way to introduce the issue of suicide in a busy epilepsy clinic, by simply asking the patient why he or she has answered in that way item 4, and whether he or she already has a plan. This will also stimulate epilepsy centres to develop shared care pathways with liaison psychiatric services in order to assess whether the person has adequate social support and is aware of sources of help; to arrange help appropriate to the level of risk; and to advise the person to seek further help if the situation deteriorates. In fact, it is important to bear in mind that, aside from the already mentioned barriers, reporting suicide ideation or behaviours may be affected by complex and often conflicting cultural attitudes [67]. In May 2013, the $66^{\text {th }}$ World Health Assembly adopted the first-ever Mental Health Action Plan of the World Health Organization (WHO) of which suicide prevention is an integral part, with the goal of reducing the rate of suicide in countries by $10 \%$ by 2020 [68]. The epilepsy community should not lose this opportunity and should support the dialog between neurology and psychiatry services in the development of effective suicide prevention strategies in order to reduce mortality of patients with epilepsy.

\section{Double stigma in epilepsy: the new challenge}

The increasing attention to psychiatric comorbidities of epilepsy is bringing to light the issue of double stigma. In fact, the stigma associated with mental health problems combined to that of epilepsy probably represents a major barrier to prevention and treatment of depression and suicide in epilepsy, especially in some geographic areas. Interestingly enough, no studies investigated the issue of double stigma in epilepsy even if it is well-known in other medical conditions, for example obesity and mental health [69] or HIV and mental health [70].

Stigma towards epilepsy is present in both high-income and poor-resources countries [71] and plays a role in mood and anxiety problems in both people with epilepsy and their caregivers [72]. In low and middle income countries, $20 \%$ of mothers of children with epilepsy feel stigmatized because of their child's neurological condition [73] and the caregiver's perception of burden, together with the level of family function, are indirectly correlated with depressive symptoms in people with epilepsy via the mediating effect of caregiver depression [74]. In high-income countries, social aspects of stigma are also important determinants of anxiety and depression in epilepsy [75]. In fact, stigma can affect the more intimate life domains of people such as cohabitation and marriage. Patients with epilepsy are less likely to be married and patients suffering from the enacted stigma are significantly more likely to get divorced in comparison with people with other chronic medical conditions [76,77][78]. The US Centers for Disease Control and Prevention, Epilepsy Program, pointed that, in US, one in five patients with epilepsy lives alone and less than one in four lives in households with two adults and children [79]. Adults with epilepsy living alone may be at increased risk of injury associated with uncontrolled seizures, mood disorders and mental health issues associated with social isolation and early mortality due to SUDEP or suicide.

Persistent stigma around mental health issues is one of the key barriers to the treatment of depression, especially in ethnic minorities [80]. For example, data from the STAR*D trial show that, in US, Hispanics initiate anti-depressant medication treatment at a much lower rate than whites, and are more likely to discontinue their treatment without consulting their physician [81]. In the general population, common concerns about depression treatments 
include fears about the addictive and harmful properties of antidepressants, worries about taking too many pills, and the stigma attached to taking psychotropic medications. It is easy to figure out the impact of these concerns in patients with epilepsy with, in addition, the general belief that antidepressant can potentially lower the seizure threshold.

The double stigma associated with epilepsy and mental health problems clearly has a negative impact on prevention and care efforts. It creates a context in which patients are reluctant to acknowledge mental health issues, and has strong psychological consequences for those who have uncontrolled epilepsy, increasing social isolation and depression. Addressing stigma and discrimination in health care systems and the wider community should be an essential part of epilepsy care [82]*. In poor resource countries, stigma directly affects access to health care $[83,84]$ but living in a high-income country with better health system performance and higher health expenditure per capita does not necessarily lead to a reduction in perceived discrimination, unless the public health system invests in awareness programmes to increase public knowledge and reduce stigma [85]. Depressive symptoms and poor social supports have the greatest impact on reported felt stigma in people with epilepsy [86]. It is evident that any program dedicated to the prevention and treatment of psychiatric problems in epilepsy has to consider stigma and related factors. People living with epilepsy should be centrally involved in policy formation and service delivery. Their involvement in the planning and delivery of mental health support will similarly contribute to the development of relevant services, including peer-led initiatives, and can empower them by building selfesteem, decreasing isolation, and enabling openness about epilepsy and mental health issues. They can be become involved in a number of ways, including policy-making and strategic planning, formation of support groups, counselling programs, positive living courses, and inclusion in the training of mental health professionals. Double stigma means double challenge and for this reason it becomes even more important to invest energies and resources. Further robust data collection and surveillance to identify points of intervention are urgently needed.

\section{Conclusion}

It is now recognised that patients with epilepsy may present with a complex neuropsychiatric syndrome accompanied by depression and purpose-developed screening instruments are now available. However, data on prevention and early diagnosis are still lacking. Data on children will be of great value for the development of clinical pathways for early diagnosis of depression and suicide prevention. In fact, further studies on suicide will be of great value in order to reduce mortality in epilepsy. Suicide prevention has finally become the goal of a new WHO strategy and this is an important opportunity to further implement the management of patients at high risk such as people with epilepsy. Overcoming stigma and fighting against the double stigma of epilepsy and mental disorders will be the new challenge.

\section{Key points: (3-5 bullet points)}

Epidemiological studies suggest that depression may represent a premorbid phase in some patients with epilepsy

Double stigma probably represents a relevant barrier to diagnosis and treatment of mood disorders in epilepsy but no data is available 
Up to $13 \%$ of children with epilepsy suffer from depression but this seems to be more common in those with lower IQ, language delays or decreasing scores on neuropsychological assessment

Suicide represents $11.5 \%$ of all causes of death in epilepsy, being three times more frequent than in the general population

\section{Acknowledgments}

No assistance for the present paper.

\section{Financial support}

The author was not paid for the present paper.

\section{Conflicts of Interest}

In the past, the author has received consultancy fees from UCB Pharma, Eisai, Pfizer, Springer and Elsevier. He has also received supports from Bial and Special Products Ltd.

\section{References}

[1] Mula M. Neuropsychiatric symptoms of epilepsy. London: Springer; 2015.

[2] Temkin O. The Falling Sickness. Baltimore: The Johns Hopkins University Press; 1994.

[3] Fisher RS, Acevedo C, Arzimanoglou A, Bogacz A, Cross JH, Elger CE, et al. ILAE Official Report: A practical clinical definition of epilepsy. Epilepsia 2014;55:475-82. doi:10.1111/epi.12550.

[4] Lin JJ, Mula M, Hermann BP. Uncovering the neurobehavioural comorbidities of epilepsy over the lifespan. Lancet 2012;380:1180-92. doi:10.1016/S01406736(12)61455-X.

[5] Boylan LS, Flint LA, Labovitz DL, Jackson SC, Starner K, Devinsky O. Depression but not seizure frequency predicts quality of life in treatment-resistant epilepsy. Neurology 2004;62:258-61.

[6] Cramer JA, Blum D, Reed M, Fanning K. The influence of comorbid depression on seizure severity. Epilepsia 2003;44:1578-84. doi:28403 [pii].

[7] Mula M, von Oertzen TJ, Cock HR, Lozsadi DA, Agrawal N. Clinical correlates of memory complaints during AED treatment. Acta Neurol Scand 2016;134:368-73. doi:10.1111/ane.12553.

[8] Hitiris N, Mohanraj R, Norrie J, Sills GJ, Brodie MJ. Predictors of pharmacoresistant 
epilepsy. Epilepsy Res 2007;75:192-6. doi:10.1016/j.eplepsyres.2007.06.003.

[9] Kanner AM. Depression in epilepsy: a complex relation with unexpected consequences. Curr Opin Neurol 2008;21:190-4. doi:10.1097/WCO.0b013e3282f4e97800019052-200804000-00015 [pii].

[10] Gilliam FG, Barry JJ, Hermann BP, Meador KJ, Vahle V, Kanner AM. Rapid detection of major depression in epilepsy: a multicentre study. Lancet Neurol 2006;5:399-405. doi:S1474-4422(06)70415-X [pii]10.1016/S1474-4422(06)70415-X.

[11] Seo J-G, Cho YW, Lee S-J, Lee J-J, Kim J-E, Moon H-J, et al. Validation of the generalized anxiety disorder-7 in people with epilepsy: a MEPSY study. Epilepsy Behav 2014;35:59-63. doi:10.1016/j.yebeh.2014.04.005.

[12] Hesdorffer DC, Ishihara L, Mynepalli L, Webb DJ, Weil J, Hauser WA. Epilepsy, suicidality, and psychiatric disorders: A bidirectional association. Ann Neurol 2012;72:184-91. doi:10.1002/ana.23601.

[13] Adelow C, Andersson T, Ahlbom A, Tomson T. Hospitalization for psychiatric disorders before and after onset of unprovoked seizures/epilepsy. Neurology 2012;78:396-401. doi:WNL.0b013e318245f461 [pii]10.1212/WNL.0b013e318245f461.

[14] Forsgren L, Nystrom L. An incident case-referent study of epileptic seizures in adults. Epilepsy Res 1990;6:66-81.

[15] Hesdorffer DC, Hauser WA, Annegers JF, Cascino G. Major depression is a risk factor for seizures in older adults. Ann Neurol 2000;47:246-9. doi:10.1002/15318249(200002)47:2<246::AID-ANA17>3.0.CO;2-E.

[16] Hesdorffer DC, Allen Hauser W, Olafsson E, Ludvigsson P, Kjartansson O. Depression and suicide attempt as risk factors for incident unprovoked seizures. Ann Neurol 2006;59:35-41. doi:10.1002/ana.20685.

[17] Alper K, Schwartz KA, Kolts RL, Khan A. Seizure incidence in psychopharmacological clinical trials: an analysis of Food and Drug Administration (FDA) summary basis of approval reports. Biol Psychiatry 2007;62:345-54. doi:S0006-3223(06)01196-6 [pii]10.1016/j.biopsych.2006.09.023.

[18] Kanner AM. Can neurobiological pathogenic mechanisms of depression facilitate the development of seizure disorders? Lancet Neurol 2012;11:1093-102. doi:10.1016/S1474-4422(12)70201-6.

[19] Mazarati A, Siddarth P, Baldwin RA, Shin D, Caplan R, Sankar R. Depression after status epilepticus: Behavioural and biochemical deficits and effects of fluoxetine. Brain 2008;131:2071-83. doi:10.1093/brain/awn117.

[20] Jobe PC. Common pathogenic mechanisms between depression and epilepsy: an experimental perspective. Epilepsy Behav 2003;4 Suppl 3:S14-24. doi:S152550500300221X [pii].

[21] Brennan TJ, Seeley WW, Kilgard M, Schreiner CE, Tecott LH. Sound-induced seizures in serotonin 5-HT2c receptor mutant mice. Nat Genet 1997;16:387-90. doi:10.1038/ng0897-387. 
[22] Kumar G, Couper A, O’Brien TJ, Salzberg MR, Jones NC, Rees SM, et al. The acceleration of amygdala kindling epileptogenesis by chronic low-dose corticosterone involves both mineralocorticoid and glucocorticoid receptors.

Psychoneuroendocrinology 2007;32:834-42. doi:10.1016/j.psyneuen.2007.05.011.

[23] Galtrey CM, Mula M, Cock HR. Stress and epilepsy: fact or fiction, and what can we do about it? Pract Neurol 2016;16:270-8. doi:10.1136/practneurol-2015-001337. ** Comprehansive overview on the role of stress in epilepsy

[24] Gélisse P, Genton P, Coubes P, Tang NPL, Crespel A. Can emotional stress trigger the onset of epilepsy? Epilepsy Behav 2015;48:15-20. doi:10.1016/j.yebeh.2015.05.010.

[25] MacKenzie G, Maguire J. Chronic stress shifts the GABA reversal potential in the hippocampus and increases seizure susceptibility. Epilepsy Res 2015;109:13-27. doi:10.1016/j.eplepsyres.2014.10.003.

[26] Reddy DS. Role of hormones and neurosteroids in epileptogenesis. Front Cell Neurosci 2013;7:1-20. doi:10.3389/fncel.2013.00115.**Interesting overview of the role of hormones and neurosteroids in epiletogenesis

[27] Rajkowska G, O’Dwyer G, Teleki Z, Stockmeier CA, Miguel-Hidalgo JJ. GABAergic neurons immunoreactive for calcium binding proteins are reduced in the prefrontal cortex in major depression. Neuropsychopharmacology 2007;32:471-82. doi:10.1038/sj.npp.1301234.

[28] Zarate CA, Singh JB, Carlson PJ, Brutsche NE, Ameli R, Luckenbaugh DA, et al. A Randomized Trial of an N-methyl-D-aspartate Antagonist in Treatment-Resistant Major Depression. Arch Gen Psychiatry 2006;63:856-64. doi:10.1001/archpsyc.63.8.856.

[29] Mula M. Investigational new drugs for focal epilepsy. Expert Opin Investig Drugs 2015;3784:1-5. doi:10.1517/13543784.2016.1110144.

[30] Franz L, Angold A, Copeland W, Costello EJ, Towe-Goodman N, Egger H. Preschool anxiety disorders in pediatric primary care: prevalence and comorbidity. J Am Acad Child Adolesc Psychiatry 2013;52:1294-303.e1. doi:10.1016/j.jaac.2013.09.008.

[31] Costello EJ, Egger HL, Angold A. The developmental epidemiology of anxiety disorders: phenomenology, prevalence, and comorbidity. Child Adolesc Psychiatr Clin N Am 2005;14:631-48, vii. doi:10.1016/j.chc.2005.06.003.

[32] Kendall PC, Compton SN, Walkup JT, Birmaher B, Albano AM, Sherrill J, et al. Clinical characteristics of anxiety disordered youth. J Anxiety Disord 2010;24:360-5. doi:10.1016/j.janxdis.2010.01.009.

[33] Kim-Cohen J, Caspi A, Moffitt TE, Harrington H, Milne BJ, Poulton R. Prior juvenile diagnoses in adults with mental disorder: developmental follow-back of a prospectivelongitudinal cohort. Arch Gen Psychiatry 2003;60:709-17. doi:10.1001/archpsyc.60.7.709.

[34] Connolly SD, Bernstein G a. Practice parameter for the assessment and treatment of children and adolescents with anxiety disorders. J Am Acad Child Adolesc Psychiatry 2007;46:267-83. doi:10.1097/01.chi.0000246070.23695.06. 
[35] Berg AT, Caplan R, Hesdorffer DC. Psychiatric and neurodevelopmental disorders in childhood-onset epilepsy. Epilepsy Behav 2011;20:550-5. doi:S1525-5050(10)007985 [pii]10.1016/j.yebeh.2010.12.038.

[36] Russ SA, Larson K, Halfon N. A national profile of childhood epilepsy and seizure disorder. Pediatrics 2012;129:256-64. doi:10.1542/peds.2010-1371.

[37] Reilly C, Atkinson P, Das K, Chin R. Neurobehavioral Comorbidities in Children With Active Epilepsy: A Population-Based Study. Pediatrics 2014;133:1586-03. doi:10.1542/peds.2013-3787.

[38] Buelow JM, Austin JK, Perkins SM, Shen J, Dunn DW, Fastenau PS. Behavior and mental health problems in children with epilepsy and low IQ. Dev Med Child Neurol 2003;45:683-92.

[39] Caplan R, Siddarth P, Gurbani S, Hanson R, Sankar R, Shields WD. Depression and anxiety disorders in pediatric epilepsy. Epilepsia 2005;46:720-30. doi:EPI43604 [pii]10.1111/j.1528-1167.2005.43604.x.

[40] Austin JK, Perkins SM, Johnson CS, Fastenau PS, Byars AW, deGrauw TJ, et al. Selfesteem and symptoms of depression in children with seizures: relationships with neuropsychological functioning and family variables over time. Epilepsia 2010;51:2074-83. doi:10.1111/j.1528-1167.2010.02575.x.

[41] Dunn DW, Austin JK, Perkins SM. Prevalence of psychopathology in childhood epilepsy: categorical and dimensional measures. Dev Med Child Neurol 2009;51:36472. doi:DMCN3172 [pii]10.1111/j.1469-8749.2008.03172.x.

[42] Ettinger AB, Ottman R, Lipton RB, Cramer JA, Fanning KM, Reed ML. Attentiondeficit/hyperactivity disorder symptoms in adults with self-reported epilepsy: Results from a national epidemiologic survey of epilepsy. Epilepsia 2015;56:218-24. doi:10.1111/epi.12897.

[43] Thapar A, Cooper M. Attention deficit hyperactivity disorder. Lancet (London, England) 2015;387:1240-50. doi:10.1016/S0140-6736(15)00238-X.

[44] Baldin E, Hesdorffer DC, Caplan R, Berg AT. Psychiatric disorders and suicidal behavior in neurotypical young adults with childhood-onset epilepsy. Epilepsia 2015;56:1623-8. doi:10.1111/epi.13123.

[45] Dunn DW, Austin JK, Huster GA. Symptoms of depression in adolescents with epilepsy. J Am Acad Child Adolesc Psychiatry 1999;38:1132-8. doi:S08908567(09)63211-1 [pii]10.1097/00004583-199909000-00017.

[46] Rodenburg R, Marie Meijer A, Dekovic M, Aldenkamp AP. Family predictors of psychopathology in children with epilepsy. Epilepsia 2006;47:601-14. doi:EPI475 [pii]10.1111/j.1528-1167.2006.00475.x.

[47] Ferro MA, Speechley KN. Depressive symptoms among mothers of children with epilepsy: a review of prevalence, associated factors, and impact on children. Epilepsia 2009;50:2344-54. doi:EPI2276 [pii]10.1111/j.1528-1167.2009.02276.x.

[48] Bell GS, Gaitatzis A, Bell CL, Johnson AL, Sander JW. Suicide in people with epilepsy: how great is the risk? Epilepsia 2009;50:1933-42. doi:EPI2106 
[pii]10.1111/j.1528-1167.2009.02106.x.

[49] Christensen J, Vestergaard M, Mortensen PB, Sidenius P, Agerbo E. Epilepsy and risk of suicide: a population-based case-control study. Lancet Neurol 2007;6:693-8. doi:S1474-4422(07)70175-8 [pii]10.1016/S1474-4422(07)70175-8.

[50] Rai D, Kerr MP, McManus S, Jordanova V, Lewis G, Brugha TS. Epilepsy and psychiatric comorbidity: a nationally representative population-based study. Epilepsia 2012;53:1095-103. doi:10.1111/j.1528-1167.2012.03500.x.

[51] Tellez-Zenteno JF, Patten SB, Jetté N, Williams J, Wiebe S. Psychiatric comorbidity in epilepsy: A population-based analysis. Epilepsia 2007;48:2336-44.

doi:10.1111/j.1528-1167.2007.01222.x.

[52] Mendez MF, Doss RC. Ictal and psychiatric aspects of suicide in epileptic patients. Int J Psychiatry Med 1992;22:231-7.

[53] Nilsson L, Ahlbom A, Farahmand BY, Asberg M, Tomson T. Risk factors for suicide in epilepsy: a case control study. Epilepsia 2002;43:644-51. doi:epi40001 [pii].

[54] Gandy M, Sharpe L, Perry KN, Miller L, Thayer Z, Boserio J, et al. Rates of DSM-IV mood, anxiety disorders, and suicidality in Australian adult epilepsy outpatients: a comparison of well-controlled versus refractory epilepsy. Epilepsy Behav E\&B 2013;26:29-35. doi:10.1016/j.yebeh.2012.10.023.

[55] de Oliveira GN, Kummer A, Salgado J V, Filho GM, David AS, Teixeira AL. Suicidality in temporal lobe epilepsy: measuring the weight of impulsivity and depression. Epilepsy Behav 2011;22:745-9. doi:10.1016/j.yebeh.2011.09.004.

[56] Hecimovic H, Santos JM, Carter J, Attarian HP, Fessler AJ, Vahle V, et al. Depression but not seizure factors or quality of life predicts suicidality in epilepsy. Epilepsy Behav 2012;24:426-9. doi:10.1016/j.yebeh.2012.05.005.

[57] Hecimovic H, Salpekar J, Kanner AM, Barry JJ. Suicidality and epilepsy: a neuropsychobiological perspective. Epilepsy Behav E\&B 2011;22:77-84. doi:10.1016/j.yebeh.2011.04.059.

[58] Hesdorffer DC, Ishihara L, Webb DJ, Mynepalli L, Galwey NW, Hauser WA. Occurrence and Recurrence of Attempted Suicide Among People With Epilepsy. JAMA Psychiatry 2016;73:80-6. doi:10.1001/jamapsychiatry.2015.2516.**Excellent study on the bidirectional relationship between epilepsy and suicidal attempt

[59] Mula M. Comments on Jones JE et al. Rates and risk factors for suicide, suicidal ideation, and suicide attempts in chronic epilepsy. Epilepsy \& Behavior 2003;4(Suppl. 3):S31-38. Epilepsy Behav 2014;40:16-7. doi:10.1016/j.yebeh.2014.08.141.

[60] FDA. Antiepileptic drugs and suicidality http://www.fda.gov/ohrms/dockets/ac/08/briefing/2008-4372b1-01-FDA.pdf 2008.

[61] Mula M, Sander JW. Antiepileptic drugs and suicidality. Much ado about very little? Neurology 2010;75:300-1. doi:75/4/300 [pii]10.1212/WNL.0b013e3181ea1638.

[62] Hesdorffer DC, Berg AT, Kanner AM. An update on antiepileptic drugs and suicide: are there definitive answers yet? Epilepsy Curr 2010;10:137-45. doi:10.1111/j.1535- 
7511.2010.01382.x.

[63] Mula M, Kanner AM, Schmitz B, Schachter S. Antiepileptic drugs and suicidality: an expert consensus statement from the Task Force on Therapeutic Strategies of the ILAE Commission on Neuropsychobiology. Epilepsia 2013;54:199-203. doi:10.1111/j.15281167.2012.03688.x.

[64] Posner K, Brown GK, Stanley B, Brent DA, Yershova K V., Oquendo MA, et al. The Columbia-Suicide Severity Rating Scale: initial validity and internal consistency findings from three multisite studies with adolescents and adults. Am J Psychiatry 2011;168:1266-77. doi:10.1176/appi.ajp.2011.10111704.

[65] Hesdorffer DC, French JA, Posner K, DiVentura B, Pollard JR, Sperling MR, et al. Suicidal ideation and behavior screening in intractable focal epilepsy eligible for drug trials. Epilepsia 2013;54:879-87. doi:10.1111/epi.12128.

[66] Mula M, McGonigal A, Micoulaud-Franchi JA, May TW, Labudda K, Brandt C. Validation of rapid suicidality screening in epilepsy using the NDDIE. Epilepsia 2016;57:949-55. doi:10.1111/epi.13373.

[67] Wasserman D, Wasserman C, editors. Oxford Textbook of Suicidology and Suicide Prevention. 1 edition. Oxford; New York: OUP Oxford; 2009.

[68] Organization WH. Preventing suicide: a global imperative. World Health Organization; 2014.

[69] Mizock L. The Double Stigma of Obesity and Serious Mental Illnesses: Promoting Health and Recovery. Stigma Heal 2015;1:86-91. doi:10.1037/2376-6972.1.S.86.

[70] Rueda S, Mitra S, Chen S, Gogolishvili D, Globerman J, Chambers L, et al. Examining the associations between HIV-related stigma and health outcomes in people living with HIV/AIDS: a series of meta-analyses. BMJ Open 2016;6:e011453.

doi:10.1136/bmjopen-2016-011453.

[71] de Boer HM, Mula M, Sander JW. The global burden and stigma of epilepsy. Epilepsy Behav 2008;12:540-6. doi:10.1016/j.yebeh.2007.12.019.

[72] Seo J-G, Kim J-M, Park S-P. Perceived stigma is a critical factor for interictal aggression in people with epilepsy. Seizure 2015;26:26-31.

doi:10.1016/j.seizure.2015.01.011.

[73] Elafros M a., Bowles RP, Atadzhanov M, Mbewe E, Haworth A, Chomba E, et al. Reexamining epilepsy-associated stigma: validation of the Stigma Scale of Epilepsy in Zambia. Qual Life Res 2015;24:1483-9. doi:10.1007/s11136-014-0868-4.

[74] Han SH, Kim B, Lee SA, Korean Qo L in ESG. Contribution of the family environment to depression in Korean adults with epilepsy. Seizure 2015;25:26-31. doi:10.1016/j.seizure.2014.11.011.

[75] Peterson CL, Walker C, Shears G. The social context of anxiety and depression: Exploring the role of anxiety and depression in the lives of Australian adults with epilepsy. Epilepsy Behav 2014;34:29-33.

doi:http://dx.doi.org/10.1016/j.yebeh.2014.03.005. 
[76] Friedrich L, Taslak M, Tomasovic S, Bielen I. How does the label "epileptic" influence attitudes toward epilepsy? Seizure 2015;33:54-9.

doi:10.1016/j.seizure.2015.10.012.

[77] Riasi H, Rajabpour Sanati A, Ghaemi K. The stigma of epilepsy and its effects on marital status. Springerplus 2014;3:762. doi:10.1186/2193-1801-3-762.

[78] Tedrus GMAS, Fonseca LC, Pereira RB. Marital status of patients with epilepsy: factors and quality of life. Seizure 2015;27:66-70. doi:10.1016/j.seizure.2015.02.028.

[79] Program UCFDCAPE. Nearly one in five adults with active epilepsy lives alone based on findings from the 2010 and 2013 US National Health Interview Surveys. US Centers for Disease Control and Prevention, Epilepsy Program. Epilepsy Behav 2015;51:259-60. doi:10.1016/j.yebeh.2015.07.034.

[80] Sanchez K, Eghaneyan BH, Trivedi MH. Depression Screening and Education: Options to Reduce Barriers to Treatment (DESEO): protocol for an educational intervention study. BMC Health Serv Res 2016;16:322. doi:10.1186/s12913-0161575-3.

[81] Warden D, Trivedi MH, Wisniewski SR, Davis L, Nierenberg AA, Gaynes BN, et al. Predictors of attrition during initial (citalopram) treatment for depression: a STAR*D report. Am J Psychiatry 2007;164:1189-97. doi:164/8/1189 [pii]10.1176/appi.ajp.2007.06071225.

[82] Mula M, Sander JW. Psychosocial aspects of epilepsy: a wider approach. Br J Psychiatry Open 2016;2:270-4. doi:10.1192/bjpo.bp.115.002345.*Comprehensive overview of the psychosocial aspects of epilepsy

[83] Nehra A, Singla S, Bajpai S, Malviya S, Padma V, Tripathi M. Inverse relationship between stigma and quality of life in India: Is epilepsy a disabling neurological condition? Epilepsy Behav 2014;39C:116-25. doi:10.1016/j.yebeh.2014.07.004.

[84] Ali DB, Tomek M, Lisk DR. The effects of epilepsy on child education in Sierra Leone. Epilepsy Behav 2014;37C:236-40. doi:10.1016/j.yebeh.2014.07.007.

[85] Brigo F, Igwe SC, Ausserer H, Tezzon F, Nardone R, Otte WM. Epilepsy-related stigma in European people with epilepsy: Correlations with health system performance and overall quality of life. Epilepsy Behav 2015;42C:18-21. doi:10.1016/j.yebeh.2014.11.015.

[86] Leaffer EB, Hesdorffer DC, Begley C. Psychosocial and sociodemographic associates of felt stigma in epilepsy. Epilepsy Behav 2014;37C:104-9.

doi:10.1016/j.yebeh.2014.06.006. 